\title{
EFEKTIVITAS METODE ELEKTROKOAGULASI DALAM MENURUNKAN KANDUNGAN COD DAN TSS PADA AIR LIMBAH
}

\author{
Jubaidi, Deri Kermelita,Yusmidiarti \\ Politeknik Kesehatan Kementerian Kesehatan Bengkulu , Jurusan Kesehatan Lingkungan, \\ Jalan Indragiri Nomor 3 Padang Harapan Bengkulu \\ e-mail: jubaidiph@yahoo.com
}

\begin{abstract}
This study aims to determine the effectiveness of electro coagulation in reducing the content of COD and TSS in hospital wastewater of dr M. Yunus Bengkulu.

This type of research is the study of pre experimental pretest posttest design without control group, the sample in this study were 36 samples. Primary data was analyzed by Annova test and followed by LSD test.

The results showed that there was a decrease of $58.55 \%$ content of COD and TSS content of $63.20 \%$, LSD test results demonstrate the value of $p=0.000$, which means there is a real difference in reducing the content of the wastewater TSS Hospital dr. M.Yunus Bengkulu.
\end{abstract}

Keywords : electro coagulation, wastewater, hospital

\begin{abstract}
Abstrak : Penelitian ini bertujuan untuk mengetahui efektifitas elektrokoagulasi dalam menurunkan kandungan COD dan TSS pada air limbah rumah sakit dr M. Yunus Bengkulu.

Jenis penelitian merupakan study pre eksperimen dengan rancangan pre test post test only with out control group, sampel dalam penelitian ini sebanyak 36 sampel. Data primer dianalisis dengan uji Anova dan dilanjutkan dengan uji LSD.

Hasil penelitian menunjukkan bahwa terdapat penurunan kandungan COD sebesar 58,55\% dan kandungan TSS sebesar 63,20\%, hasil uji LSD menunjukkan nilai $\mathrm{p}=0,000$ yang berarti ada perbedaan secara nyata dalam menurunkan kandungan TSS air limbah Rumah Sakit dr. M.Yunus Bengkulu.
\end{abstract}

Kata Kunci: elektrokoagulasi, air limbah, rumah sakit.

Air limbah rumah sakit merupakan salah satu sumber pencemaran air yang sangat potensial. Air limbah rumah sakit berasal dari buangan domestik maupun buangan air limbah klinis umumnya mengadung senyawa polutan organik yang cukup tinggi, sedangkan untuk air limbah rumah sakit yang berasal dari laboratorium banyak mengandung zat-zat kimia dan logam berat, logam berat tersebut dapat mengganggu proses pengolahan secara biologi. Oleh karena itu untuk pengelolaan air limbah rumah sakit yang mengandung zat kimia dan logam berat dipisahkan pengelolaannya untuk kemudian diolah secara kimia-fisika (Said dan Marsidi, 2002).

Di Indonesia, 119 juta penduduk belum memiliki akses terhadap air bersih. Baru $20 \%$, itupun kebanyakan di daerah perkotaan, sedangkan $80 \%$ rakyat Indonesia mengkonsumsi air yang tak layak untuk kesehatan.
Dan sebanyak 60\% sungai di Indonesia tercemar oleh buangan industri termasuk limbah rumah sakit, mulai bahan organik dan anorganik sampai bakteri coli form dan fecal coli penyebab diare (Menkes, 2012).

Hasil pemeriksaan pendahuluan diketahui bahwa kualitas air limbah di Rumah Sakit dr. M.Yunus Bengkulu dengan nilai COD 668,556 mg/l dan nilai TSS 458,667 $\mathrm{mg} / \mathrm{l}$. Kondisi ini lebih tinggi bila dibandingkan dengan standar kualitas air limbah rumah sakit yaitu COD $100 \mathrm{mg} / \mathrm{l}$ dan TSS 100 mg/l. Bila air limbah ini dibuang ke badan air akan menimbulkan pencemaran yang luas sehingga menurunkan kualitas badan air.

Dampak yang ditimbulkan oleh pembuangan air limbah dari rumah sakit yang tidak diolah sempurna adalah terganggunya ekosistem lingkungan dan meningkatkan jumlah kesakitan masyarakat akibat penyakit 
tertentu seperti penyakit hepatitis, diare, polio dan sebagainya. Untuk mengatasi permasalahan air limbah rumah sakit tersebut di atas diperlukan suatu metode pengolahan air limbah yang inovasi, murah dan efisien sebelum air limbah tersebut dibuang ke lingkungan.

Parameter pencemar air limbah rumah sakit yang perlu diperhatikan adalah BOD (Biological Oxygen Demand), COD (Chemical Oxygen Demand), TSS (Total Suspended Solid) dan pH. Dalam mencegah terjadinya pemcemaran lingkungan yang disebabkan oleh perkembangan rumah sakit maka perlu upaya pengendalian pencemaran lingkungan sesuai Keputusan Menteri Lingkungan Hidup Nomor:KEP-58/MENLH/12/1995.

Untuk mengatasi permasalahan air limbah rumah sakit dr. M.Yunus Bengkulu, diperlukan suatu metode pengolahan air limbah yang efisien sebelum air limbah dibuang ke badan air. Salah satu teknik pengolahan air limbah rumas sakit adalah memakai teknik elektrokoagulasi. Proses elektrokoagulasi mereduksi ion $\mathrm{H}^{+}$pada katoda akan menghasilkan gas hydrogen $\left(\mathrm{H}_{2}\right)$. Pembentukan gas ini membantu terbentuknya flok-flok dan flok-flok ini lama kelamaan akan mengendap jika sudah mencapai berat tertentu.

Aplikasi teknik elektrokoagualsi yang telah dilakukan beberapa tahun terakhir dalam pengolahan air limbah adalah penerapan elektrokoagualsi untuk pengolahan tersier limbah cair industri pangan (Gameisa dkk, 2012), pengolahan limbah cair tekstil (Hari dan Harsanti 2010), pengolahan air limbah domestik (Iswanto dkk, 2009) dan pengolahan air limbah emulsi minyak-deterjen (Iswanto dkk, 2009). Penelitian ini bertujuan untuk mengetahui efektivitas teknik elektrokoagulasi dengan berbagai variasi jumlah kuat arus dalam penurunan kandungan COD dan TSS pada air limbah Rumah Sakit Dr. M.Yunus Bengkulu.

\section{BAHAN DAN CARA KERJA}

Bahan yang digunakan dalam penelitian ini adalah air limbah (inlet) rumah sakit dr. M. Yunus Bengkulu, Reagen $\mathrm{K}_{2} \mathrm{Cr}_{2} \mathrm{O}_{7}, \mathrm{HgSO}_{4}, \mathrm{H}_{2} \mathrm{SO}_{4}, \mathrm{MgSO}_{4}, \mathrm{FeCl}_{2}$, dan
Feroin. Peralatan yang digunakan terdiri dari eletrokoagulasiyang terbuat dari lempeng besi dan lempeng alumunium dengan ukuran masing-masing $6 \mathrm{~cm} \times 15 \mathrm{~cm}$, power supply, tandon air, beaker dan bak plastik. Proses pemeriksaan COD dan TSS dilakukan dengan memasukkan alat elektrokoagulasi (lempeng besi dan alumunium) sesuai dengan variabel penelitian yang diinginkan yaitu dengan kuat arus 3 A, 6 A dan 9 A dengan waktu tinggal 25 menit.

\section{HASIL}

Pengukuran COD dan TSS dilakukan sebelum dan sesudah proses elektrokoagulasi air limbah rumah sakit dengan total perlakuan sebanyak 36 kali perlakuan dengan hasil disajikan pada tabel berikut :

Tabel 1. Distribusi Nilai Mean, SD dan Nilai minimal dan Maksimal Kandungan COD dan TSS Air Limbah dari Rumah Sakit dr. M. Yunus Bengkulu Sebelum dan Sesudah Perlakuan Tahun 2012

\begin{tabular}{|c|c|c|c|c|}
\hline Variabel & Mean & SD & Min & Max \\
\hline \multicolumn{5}{|l|}{ Kandungan } \\
\hline \multicolumn{5}{|l|}{ COD } \\
\hline Sebelum & 661,778 & 11,410 & 650,0 & 680,0 \\
\hline \multicolumn{5}{|l|}{ Perlakuan } \\
\hline Sesudah & 313,744 & 8,153 & 295,1 & 321,5 \\
\hline \multicolumn{5}{|l|}{ Perlakuan 3 A } \\
\hline Sesudah & 291,300 & 4,396 & 284,3 & 296,3 \\
\hline \multicolumn{5}{|l|}{ Perlakuan 6 A } \\
\hline Sesudah & 274,300 & 6,894 & 263,7 & 286,3 \\
\hline \multicolumn{5}{|l|}{ Perlakuan 9 A } \\
\hline \multicolumn{5}{|l|}{ Kandungan } \\
\hline \multicolumn{5}{|l|}{ TSS } \\
\hline Sebelum & 438,667 & 22,885 & 415,0 & 486,0 \\
\hline \multicolumn{5}{|l|}{ Perlakuan } \\
\hline Sesudah & 232,889 & 15,719 & 215,0 & 261,0 \\
\hline \multicolumn{5}{|l|}{ Perlakuan 3 A } \\
\hline Sesudah & 189,556 & 17,139 & 168,0 & 217,0 \\
\hline \multicolumn{5}{|l|}{ Perlakuan 6 A } \\
\hline Sesudah & 161,444 & 18,035 & 141,0 & 194,0 \\
\hline Perlakuan 9 A & & & & \\
\hline
\end{tabular}

Tabel 1 menunjukkan bahwa dengan kuat arus 9 A kandungan COD (mean, SD, nilai minimal dan maksimal) terkecil sebelum dan sesudah perlakuan terhadap air limbah rumah sakit. Hasil analisis homogenitas terhadap data COD dan TSS air limbah rumah sakit disajikan pada tabel 2 : 
Tabel 2. Hasil Analisis Homogenitas data COD dan TSS pada Air Limbah Rumah Sakit dr. M. Yunus Bengkulu tahun 2012

\begin{tabular}{cc}
\hline Variabel & Sig \\
\hline Kandungan COD & 0,036 \\
Kandungan TSS & 0,746 \\
\hline
\end{tabular}

Tabel 2 menunjukkan hasil analisis homogenitas data COD dan TSS bahwa hanya data TSS yang homogen dengan nilai Sig. 0,746 yang akan diuji dengan uji Anova, sedangkan COD tidak homogen (Sig. 0,036) yang akan diuji dengan uji Kruskal-Willis.

Tabel 3. Hasil Analisis Perbedaan terhadap kandungan TSS pada Air Limbah Rumah Sakit dr. M. Yunus Bengkulu tahun 2012

\begin{tabular}{cc}
\hline Variabel & P Value \\
\hline Kandungan TSS & 0,000 \\
\hline
\end{tabular}

Berdasarkan tabel 3 hasil analisis $\mathrm{Uji}$ Anova antara variabel independen dan variabel dependen, menunjukkan bahwa variabel TSS mempunyai nilai $\mathrm{p}=0,000$ yang berarti terdapat perbedaan rerata kandungan TSS pada ke empat perlakuan tersebut. Kandungan COD dalam air limbah tidak dapat diuji dengan uji beda (Uji Anova) karena data COD tidak homogen (Sig. 0,036) untuk dapat dianalisis maka data COD diuji dengan uji Kruskal-Wallis yang disajikan dalam tabel 4:

Tabel 4. Hasil Uji Kruskal-Wallis terhadap kandungan COD pada Air Limbah Rumah Sakit dr. M. Yunus Bengkulu

\begin{tabular}{cc}
\hline Variabel & P Value \\
\hline Kandungan COD & 0,000
\end{tabular}

Berdasarkan tabel 4 hasil Uji KruskalWallis antara variable independen dan variabel dependen, menunjukkan bahwa kandungan COD mempunyai nilai $p=0,000$ yang berarti terdapat perbedaan yang bermakna pada rerata kandungan COD pada ke empat perlakuan tersebut.

Berdasarkan uji normalitas tabel 4, diketahui bahwa hanya terdapat variabel TSS yang homogen (Sig.0,746), untuk mengetahui ke empat perlakuan mana yang kuat pengaruhnya terhadap penurunan kandungan TSS dalam air limbah rumah sakit maka dilakukan uji Least Significantly Difference (LSD) sebagaimana tabel 5:

Tabel 5. Hasil Uji Least Significantly Difference Kandungan TSS pada air limbah Rumah Sakit Dr. M.Yunus Bengkulu

\begin{tabular}{ccccc}
\hline Variabel TSS & Perlakuan & Sig & \multicolumn{2}{c}{ Cl. 95\% } \\
\cline { 4 - 5 } & & & Lower & Upper \\
\hline Sebelum Perlakuan & 3 A & 0,000 & 187,879 & 223,677 \\
& 6 A & 0,000 & 231,212 & 267,010 \\
9 A & 0,000 & 259323 & 295,121 \\
3 A & Sebelum & 0,000 & $-223,677$ & $-187,879$ \\
& Perlakuan & & & \\
& 6 A & 0,000 & 25,434 & 61,233 \\
& 9 A & 0,000 & 53,545 & 89,344 \\
& Sebelum & 0,000 & $-267,010$ & $-231,212$ \\
& Perlakuan & & & $-25,434$ \\
& 3 A & 0,000 & $-61,233$ & 46,010 \\
& 9 A & 0,003 & 10,212 & $-259,323$ \\
& Sebelum & 0,000 & $-295,121$ & $-53,545$ \\
& Perlakuan & & & $-10,212$ \\
\hline
\end{tabular}

\section{PEMBAHASAN}

Hasil pemeriksaan pendahuluan membuktikan bahwa nilai COD Rumah Sakit dr. M.Yunus Bengkulu masih tinggi yaitu
668,556 mg/L dan nilai TSS sebesar 458,667 $\mathrm{mg} / \mathrm{L}$. Besarnya nilai COD dan TSS air limbah rumah sakit oleh karena rusaknya sebagian kecil alat pengolah IPAL di Rumah Rakit dr. M. Yunus Bengkulu, sehingga air 
limbah dibuang dengan pengolahan yang tidak sempurna.

Tabel 1 menunjukkan bahwa nilai COD sebelum perlakuan rerata sebesar 661,778 $\mathrm{mg} / \mathrm{L}$ dan nilai COD setelah perlakuan rerata $274,300 \mathrm{mg} / \mathrm{L}$ pada kuat arus 9 Ampere dengan waktu kontak 25 menit. Dengan nilai COD tersebut maka limbah rumah sakit dr. M.Yunus Bengkulu belum dapat memenuhi baku mutu ling-kungan dan tergolong dalam kategori limbah yang mencemari lingkungan. Namun pe-ngolahan air limbah memakai teknik elek-trokoagulasi mampu menurunkan kandungan COD air limbah rumah sakit sebesar $58,55 \%$. Uji statistik yang dilakukan untuk me-ngetahui adanya perbedaan (uji Anova) tidak dapat dilakukan karena data COD tidak homogen (Sig. 0,036), namun dengan uji Kruskal-Wallis (tabel 2) bahwa nilai COD dalam air limbah rumah sakit bermakna $(p=0,000)$ yang berarti ada perbedaan rerata secara nyata untuk keempat perlakuan tersebut.

Dari tabel 5 menunjukkan bahwa makin tinggi kuat arus yang diberikan dengan waktu kontak 25 menit maka penurunan nilai COD pada air limbah semakin besar. Berdasarkan penelitian yang dilakukan oleh Iswanto, Silalahi dan Ayuningtyas (2009) bahwa proses pengolahan air limbah dengan teknik elektrokoagualsi mampu menurunkan nilai COD sebesar 95,54\% pada pengolahan air limbah emulsi minyak-detergen memakai elektroda alumunium.

Hasil penelitian sejenis yang dilakukan oleh Gamessia, Suprihatin dan Indrasti (2012) pada pengolahan tersier limbah cair industri pangan memakai teknik elektrokoagulasi yang menggunakan elektroda stainless steel menunjukkan bahwa ada efisiensi penurunan kandungan COD sebesar $77,78 \%$

Tabel 2 menunjukkan bahwa nilai TSS atau totatl padatan tersuspensi adalah padatan yang tersuspensi di dalam air limbah berupa bahan-bahan organik dan inorganik (Said, 2006). Pada Tabel 5 dapat dilihat bahwa teknik elektrokoagulasi memberikan pengaruh terhadap penurunan nilai TSS yang signifikan. Nilai TSS air limbah rumah sakit seb- elum dilakukan proses elektrokoagulasi sebesar 438,667 mg/L dan nilai TSS setelah perlakuan rerata $161,444 \mathrm{mg} / \mathrm{L}$ pada kuat arus 9 Amper dengan waktu kontak 25. Dengan nilai TSS tersebut maka limbah rumah sakit dr. M.Yunus Bengkulu belum dapat memenuhi baku mutu lingkungan dan tergolong dalam kategori limbah yang mencemari lingkungan. Namun pengolahan air limbah dengan teknik elektrokoagulasi mampu menurunkan kandungan TSS air limbah rumah sakit sebesar $63,20 \%$.

Hasil uji homogenitas terhadap data TSS menunjukkan nilai Sig. 0,746, yang berarti data TSS homogen dan selanjutnya dilakukan uji Anova untuk mengetahui perbedaan kuat arus dalam penurunan nilai TSS air limbah Rumah Sakit dr. M. Yunus Bengkulu (tabel 2) menunjukkan nilai $p=0,000$ yang berarti terdapat perbedaan rerata nilai TSS pada ke empat perlakuan tersebut. Selanjutnya dilakukan uji LSD untuk mengetahui perlakuan mana yang paling tinggi dalam menurunkan nilai TSS pada air limbah rumah sakit dr. M. Yunus Bengkulu, dari hasil analisis ini (tabel 5) menunjukkan seluruh perlakuan signifikan (Sig.0,000) yang berarti keempat perlakuan tersebut efisien dalam menurukan nilai TSS air limbah rumah sakit dengan waktu kontak 25 menit.

Berdasarkan penelitian yang dilakukan oleh Gamessia, Suprihatin dan Indrasti (2012) pada pengolahan tersier limbah cair industri pangan dengan teknik elektrokoagulasi menggunakan elektroda stainless steel menunjukkan bahwa ada efisiensi penurunan kandungan TSS sebesar $88,02 \%$. Hasil penelitian sejenis dengan efisiensi lebih tinggi yang dilakukan oleh Iswanto, Silalahi dan Ayuningtyas (2009) bahwa proses pengolahan air limbah dengan teknik elektrokoagualsi mampu menurunkan nilai TSS sebesar $98,94 \%$ pada pengolahan air limbah domestik menggunakan elektroda alumunium.

Teknik elektrokoagulasi dapat digunakan untuk meningkatkan kualitas air limbah sehingga air limbah yang diolah memenuhi baku mutu lingkungan sebagaimana SK Menteri KLH Nomor 58 tahun 1995 
tentang baku mutu lingkungan. Variasi kuat arus dan waktu kontak elektrokoagulasi sebelum dan sesudah perlakuan mempengaruhi penurunan nilai COD dan nilai TSS dalam air limbah.

Teknik elektrokoagulasi merupakan proses pembentukan endapan dan flok-flok yang terapung (flotation) (Said, 2002), hal ini sebagai indikasi bahwa ion-ion $\mathrm{Al}+2$ mengikat polutan atau zat terlarut sangat efektif. Pengolahan air limbah rumah sakit dengan teknik elektrokoagulasi ini masih terdapat kekurangan yaitu tidak dilakukan analisis terhadap luas permukaan lempeng besi, lempeng alumunium dan luas bak air limbah, serta parameter lain seperti zat organik, zatzat kimia dan B3 sehingga teknik elektrokoagulasi belum optimal untuk diaplikasikan dalam pengolahan air limbah dalam sekala besar. Menurut Said (2002) bahwa air limbah organik dan air limbah anorganik dari rumah sakit pengolahannya harus dipisahkan, jika tidak akan mempengaruhi proses pengolahan air limbah. Selanjutnya Susanto, Wijaya dan Ganefati (2002) mengemukakan bahwa pengolahan air limbah harus disesuaikan dengan karakteristik air limbah yang dihasilkan oleh suatu industri termasuk rumah sakit.

\section{KESIMPULAN}

Kandungan COD rerata sebelum perlakuan $661,778 \mathrm{mg} / \mathrm{L}$ dan kandungan TSS 438,667 mg/L serta sesudah perlakuan rerata

\section{DAFTAR RUJUKAN}

Agnes A.R., R. Azizah, 1999. Perbedaan Kadar BOD, COD, TSS. Jakarta

Anwar Hadi, 2003. Prinsip Pengelolaan Pengambilan Sampel Lingkungan. Jakarta: Gramedia Indonesia

Arifin, Pengaruh Limbah Rumah Sakit Terhadap Kesehatan. Jurnal. (http://www.pontianakpost.com)

Ayuningtyas, 2009. Proses Pengolahan Air Limbah Dengan Teknik Elektrokoagualsi pada Pengolahan Air Limbah Emulsi MinyakDetergen dengan Menggunakan Elektroda Alumunium.

Darmanto dan Supardi, 2005. Menejemen Lingkungan Rumah Sakit. Yogyakarta: Gadjah Mada Press. penurunan kandungan COD dengan kuat arus $3 \mathrm{~A}$ sebesar $313,744 \mathrm{mg} / \mathrm{L}$, pada kuat arus $6 \mathrm{~A}$ sebesar 291,300 mg/L dan pada kuat arus 9A sebesar 274,300 mg/L sedangkan kandungan TSS pada kuat arus 3A sebesar 233,2889 $\mathrm{mg} / \mathrm{L}$, pada kuat arus 6 A sebesar 189,556 $\mathrm{mg} / \mathrm{L}$ dan pada kuat arus 9 A sebesar $161,444 \mathrm{mg} / \mathrm{L}$.

Jumlah kandungan COD sebelum perlakuan sebanyak $661,778 \mathrm{mg} / \mathrm{L}$ setelah pengolahan melalui teknik elektrokoagualasi efisiensi tertinggi sebesar $58,55 \%$ terjadi pada kuat arus 9 A menjadi $274 \mathrm{mg} / \mathrm{L}$. Sedangkan kandungan TSS sebelum perlakuan sebesar 438,667 $\mathrm{mg} / \mathrm{L}$ dengan teknik elektrokoagulasi dalam pengolahan air limbah rumah sakit terdapat efisiensi tertinggi $63,20 \%$ terjadi pada kuat arus 9A menjadi $161,444 \mathrm{mg} / \mathrm{L}$.

Hasil Uji LSD menunjukkan nilai $\mathrm{p}=0,0$ yang berarti ada perbedaan secara nyata dalam menurunkan kandungan TSS air limbah Rumah Sakit dr. M. Yunus sebelum dan sesudah perlakuan.

Disarankan kepada Rumah Sakit dr. M. Yunus Bengkulu, untuk segera menurunkan kandungan COD dan kandungan TSS sesuai standar kualitas air limbah. Bagi masyarakat, dalam memanfaatkan sumber air bersih, agar diolah terlebih dahulu sebelum digunakan, dan bagi peneliti lain, diharapkan dapat melanjutkan penelitian ini dengan melengkapi variabel yang lain.

Gameisa, dkk, 2012. Penerapan Elektrokoagualsi untuk Pengolahan Tersier Limbah Cair Industri Pangan dengan Menggunakan Elektroda Stainless Steel.

Hari dan Harsanti, 2010. Pengolahan Limbah Cair Tekstil.

Iswanto, Silalahi Dan Purnama, 2009. Pengolahan Air Limbah Emulsi Minyak Detergen dengan Proses Elektrogulan Menggunakan Elektrodaalumunium, Jurnal Teknologi Lingkungan, Volume 5 No. 2; ISSN: 1829-6572

Kementerian Lingkungan Hidup, 1995. Keputusan Menteri Lingkungan Hidup Nomor:KEP58MENLH/12/1995 tentang parameter air limbah rumah sakit antara Biological Oxygen 
Demand (BOD), Chemical Oxygen Demand (COD), Total Suspended Solid (TSS) dan pH.

LIPI, 2007. Pengelolaan Limbah Rumah Sakit, Jakarta

LKPK, 2006. Limbah Rumah Sakit, Perlu Pengelolaan dan Monitoring. Jakarta

Ginting, P., 2010. System Pengelolaan Lingkungan dan Limbah Industry. Irama Widya. ISBN 978979-543-582-2

Said, NI, 2002. Tehnologi Pengolahan Limbah Cair Industry. Jurnal BPPT Jakarta. ISBN:978-846538-5

Said dan Marsidi, 2002. Pengelolaan Air Limbah Rumah Sakit yang Mengandung Zat Kimia dan Logam Berat secara Kimia-Fisika.
Setiyono, 2002. Sistem Pengolaan Limbah B3 Di Indonesia. Jurnal BPPT. Jakarta. ISBN:9798465-38-5 ---, 2002. Materi Pelatihan Pengelolaan Limbah Cair. BPPT. Jakarta, ISBN: 978-979-8465-54-3 Susanto, Wijaya dan Ganefati, 2002. Pengolahan Air Limbah Rumah Sakit.

Susetyaningsih, Kismolo Dan Prayitno, 2008. Kajian Proses Elektrokoagulasi untuk Pengelolaan Limbah Cair, Yogyakarta, Seminar Nasional IV SDM Teknologi Nuklir, ISSN 1978-0176, 2008. 